CORPUS $\begin{aligned} & \text { Corpus } \\ & \text { Archivos virtuales de la alteridad americana }\end{aligned}$

Vol 3, No $1 \mid 2013$

Enero / Junio 2013

\title{
Cartas Guarani. O uso presente de papeis do passado
}

Guarani letters. The present use of papers from the past

Pablo Antunha Barbosa, Daniel Calazans Pierri y Marco Antonio Barbosa

\section{(2) OpenEdition}

Journals

Edición electrónica

URL: http://journals.openedition.org/corpusarchivos/419

DOI: 10.4000/corpusarchivos.419

ISSN: $1853-8037$

Editor

Diego Escolar

Referencia electrónica

Pablo Antunha Barbosa, Daniel Calazans Pierri y Marco Antonio Barbosa, «Cartas Guarani. O uso presente de papeis do passado », Corpus [En línea], Vol 3, No 1 | 2013, Publicado el 15 junio 2013, consultado el 19 abril 2019. URL : http://journals.openedition.org/corpusarchivos/419 ; DOI :

10.4000/corpusarchivos.419

Este documento fue generado automáticamente el 19 abril 2019.

Licencia Creative Commons: Atribución-NoComercial 2.5 Argentina (CC BY-NC 2.5 AR) 


\title{
Cartas Guarani. O uso presente de papeis do passado
}

\author{
Guarani letters. The present use of papers from the past
}

Pablo Antunha Barbosa, Daniel Calazans Pierri y Marco Antonio Barbosa

1 As duas cartas que seguem são interessantes por inúmeros motivos. Em primeiro lugar, porque até a presente data não há notícias sobre a existência de outros documentos redigidos por indígenas Guarani do Estado de São Paulo no início do século XX que tratem de problemas ligados a terra. Em segundo lugar, porque essas cartas indicam os contornos nos quais se operou o processo de ocupação e espoliação dos territórios indígenas no Estado de São Paulo nas primeiras décadas do período republicano. Por fim, e levando-se em consideração a situação contemporânea dos Guarani no litoral do Brasil, essas duas cartas não somente desmentem a posição daqueles que negam com veemência a continuidade histórica da ocupação guarani na região do Vale do Ribeira, como também revelam uma longa trajetória Guarani na "luta" pela manutenção de seus territórios tradicionais no litoral do Estado de São Paulo.

2 Ambas as cartas que ora se publicam por primeira vez constam do fundo "Benedito Calixto" do Arquivo Público do Estado de São Paulo (APESP) e foram reproduzidas recentemente em dois relatórios antropológicos da Fundação Nacional do Índio (FUNAI) elaborados como peças administrativas relacionadas ao processo de regularização das Terras Indígenas Guarani do Estado de São Paulo ${ }^{1}$. Estas duas cartas foram redigidas por volta de 1907 por dois Guarani pertencentes ao antigo aldeamento do Rio Itariri e tinham como claro objetivo solicitar o auxílio do historiador, pintor e amigo Benedito Calixto ${ }^{2}$ frente a um iminente processo de expulsão de seus territórios. 0 antigo aldeamento do Rio Itariri, por sua vez, também conhecido na documentação histórica como aldeamento do Rio do Peixe, por se localizar justamente na confluência dos dois mencionados rios, guarda registros de uma vida legal de aproximadamente oitenta anos, tendo sido oficialmente criado pelo Estado brasileiro por volta dos primeiros anos da década de 1840 . Não há registro formal de sua extinção, mas nota-se que os documentos sobre esse aldeamento desaparecem poucos anos após a redação das presentes cartas. É de se supor que provavelmente por volta da primeira metade da segunda década do século XX o 
referido aldeamento tenha sido abandonado pelo governo do Estado de São Paulo à sua própria sorte, embora a ocupação guarani no Rio Itariri nunca tenha deixado de existir. De fato, a persistência dos Guarani em se manterem na região levou ao reconhecimento tardio pelo Serviço de Proteção aos Índios (SPI) do Posto Indígena Carvalho Pinto na década de 1950 e, posteriormente, já na década de 1980 foi reconhecida a atual Terra Indígena Serra do Itatins, ambas áreas nas proximidades do antigo aldeamento mencionado nas cartas.

$\mathrm{O}$ ato de oficialização do antigo aldeamento do Itariri está relacionado a uma série de conflitos causados após diversas tentativas frustradas das autoridades locais em tentar "capturar" os Guarani que viviam "dispersos" nas adjacências do vale do rio Ribeira de Iguape para, em seguida, distribuí-los individualmente como "empregados domésticos" entre as famílias ricas dos diferentes distritos do município de Iguape. Nota-se que o desmembramento das famílias indígenas para serem entregues entre os "civilizados" era uma prática corriqueira e legalizada até meados do século XIX. No entanto, após uma série de episódios conflituosos que causaram a morte de alguns colonos locais, episódios esses que ainda hoje são lembrados entre os Guarani da região, o Governo não teve outra alternativa a não ser disponibilizar uma parcela de terras para o uso exclusivo dos indígenas. Não existindo ato formal de extinção do referido aldeamento, pode-se dizer que durante seus oitenta anos de existência legal, foram praticadas diversas ações que buscavam a "extinção" e "assimilação" dos indígenas que ali habitavam. Esse processo, como se verá mais adiante, perdurou durante o período de atuação do SPI na região.

4 As cartas aqui transcritas revelam justamente o momento mais violento dessa pressão que visava o esbulho do antigo aldeamento do Rio Itariri. Tanto na primeira carta, escrita pela indígena Benedicta Ribeiro em fevereiro de 1907, como na segunda, redigida contemporaneamente por José Pupo Ferreira, é possível perceber que a "cisma" manifestada pelos Guarani era totalmente legítima, uma vez que diversos lotes de terras dentro dos limites do aldeamento vinham sendo apropriados pelo próprio encarregado do aldeamento, José Baptista Ribeiro, e seu irmão, Bento Manuel Ribeiro. Contudo, os parentes do inspetor Ribeiro não foram os únicos particulares que se favoreceram com a apropriação de lotes dentro dos limites do aldeamento do Itariri. Num relato feito nos anos 1980 pelo finado capitão Antônio Branco ${ }^{3}$, ele menciona a atuação decisiva de um tal Vasconcelos que levou os indígenas a deixarem as margens do rio Itariri e do Peixe para se localizarem no alto da serra do Itatins, já nas margens do rio do Azeite. De fato, o personagem mencionado pelo capitão Antônio Branco é o mesmo Raymundo Vasconcelos conhecido por ter liderado a criação da povoação de Alecrim e da fazenda São José no ano de 1912. Esta povoação, criada inicialmente como uma das distintas estações da recémcriada estrada de ferro que ligava as cidades de Santos e Juquiá, poucos anos depois se transformaria na cidade de Pedro de Toledo. Ao fazer o exercício de sobrepor os mapas antigos disponíveis sobre a região, é possível perceber que a atual cidade de Pedro de Toledo se localiza exatamente na confluência dos rios do Peixe e Itariri; em outras palavras, Pedro de Toledo foi erguida voluntariamente sobre as benfeitorias do antigo aldeamento indígena e a revelia dos Guarani, resultando em esbulho irreversível de parte do território de ocupação indígena.

5 Após mais de duas décadas de reivindicações Guarani pela demarcação de novas Terras Indígenas (T.I.) na região do Vale do Ribeira, no litoral sul do Estado de São Paulo, a Fundação Nacional do Índio (FUNAI) instituiu, em 2009, três Grupos Técnicos (GT) compostos principalmente por antropólogos e ambientalistas com objetivo de elaborar 
relatórios que identifiquem e delimitem as atuais áreas reivindicadas pelos Guarani. No entanto, uma das principais dificuldades na elaboração destes estudos, que constituem sem dúvida a principal peça administrativa do processo de demarcação de Terras Indígenas no Brasil, é a relativa escassez de documentos históricos que atestem a tradicionalidade da ocupação guarani na região. Paralelamente a esse problema de "invisibilidade" na historiografia, é de se considerar também outro problema já conhecido relativo ao fato de que os registros escritos existentes fazem referência a uma sociedade que fez pouco uso da escrita, apesar da existência das cartas que ora se publicam, se comparada a outras sociedades indígenas, como a Mapuche, por exemplo (Pavez Ojeda 2008). De um lado, essas cartas mostram o esforço notável de alguns indivíduos guarani na mobilização da linguagem escrita para defesa de seus próprios interesses. De outro, mesmo em não se tratando de documento "oficial", direcionado à administração estatal, essas cartas se produzem no contexto de uma interface com esse poder, sendo regidas pelas regras que lhe são próprias.

6 Para ilustrar esse argumento, vale a pena citar trechos de um relatório, esse sim oficial, redigido em 1955 por um funcionário do SPI a respeito da ocupação guarani do Rio Itariri e Azeite e que resultou, posteriormente, no reconhecimento oficial desta localidade como Posto Indígena:

7 3. Encontrei nove (9) famílias compostas de trinta e um (31) membros guaranis, todas em suas casas (de palha), nas terras da cabeceira do conhecido Rio Azeite, no atual município de Itariri (Estado de São Paulo). Existem ainda fora da dita aldeia treze (13) famílias compostas de quarenta e cinco (45) guaranis, estando dos referidos: vinte e cinco (25) pessoas na Fazenda de Bertioga, em Santos (Interior); e as outras vinte (20) em outras Fazendas na zona de Cananeia. [...]

8 5. Os ditos guarani do rio Azeite tinham outrora a sua aldeia no atual lugar denominado Pedro Toledo. Com as constantes aproximações dos fazendeiros agricultores naquela região obrigaram-nos a recuar; cujos índios aldearam-se nas adjacências da cachoeira do rio Azeite, por onde, na dita zona, passa a estrada que está sendo construída pelo fazendeiro agricultor (alto latifundiário), senhor José Pentenari. [...]

Conforme as informações que dão as pessoas mais antigas de Itariri, os guaranis nunca se retiraram totalmente daquela região. Alguns deles, em grupos, as vezes saiam para visitar seus parentes em outros lugares e demoravam certos tempos; isso é natural da vida silvícola; contudo regressavam ao seu "habitat" de costume. As provas de que os guaranis moravam em dito lugar (das cabeceiras do rio Azeite) desde que as terras dali eram devolutas, se vê pelas suas roças velhas e casas. [...] E nesse sentido opinou o Sr. Dr. Francisco Teixeira Leite, chefe de uma das Seções no dito Departamento, que em vista de tal situação embaraçosa a solução seria resolvida satisfatoriamente com a transferência dos índios para as terras já cedidas pelo Estado de São Paulo aos índios, no município de Itanhaém. Acontece, porém, que os índios/guaranis do rio Azeite amam o lugar em que vivem e não querem se retirar de lá. Fiz ver isso ao distinto Sr. Dr. Francisco Teixeira Leite e, diante disso, ele apresentou outra sugestão. Mostrou ele no mapa que próximo a zona onde habitam os índios, há uns nove (9) quilômetros mais ou menos, tem uma importante gleba de aproximadamente seiscentos (600) hectares de terras devolutas do Estado de São Paulo, para a qual poderiam ser transferidos os guaranis. Anexo se vê o mapa e no mesmo, na parte pontilhada a tinta de escrever, acham-se dispostos em vários lotes as moradas dos índios. Em dito mapa podese ter uma noção completa das divisões por lotes das terras. Os guaranis estão espalhados, 
próximos, entre si, nos diversos lotes. Eles, guaranis, não tem noção compacta do que sejam as divisões de terras; como através de muitos anos vivem ali, se acham com o direito às terras e consideram que os posseiros são invasores. Nesse mapa indica a área de terras que devera ser cedida ao S.P.I. (Albuquerque, 1955, grifos nossos)

Embora distante em cerca de 50 anos no tempo, esse documento dialoga muito com as Cartas Guarani ora publicadas. De saída, deve-se notar que o funcionário do SPI, que tinha como propósito reconhecer a ocupação guarani no Rio do Azeite, aponta como pertencentes ao local tanto os 31 indígenas que lá residiam, como também os outros 45 que viviam, em parte, na região de Bertioga e, em parte, na região de Cananéia, ambos espaços que também compõe a região do Vale do Ribeira. É interessante notar que a população que vivia fora do que viria a ser o futuro Posto Indígena era maior do que a população que lá residia. Assim, tanto neste documento como nas Cartas Guarani se manifesta uma limitação fundamental das chamadas "fontes escritas", uma vez que a ocupação indígena se refere na maioria dos casos apenas à considerada "oficial" ou, ao menos, com a pretensão de sê-la. As lógicas reais da territorialidade assim como sua presença em outras localidades nunca são reconhecidas pelo Estado que só se refere aos indígenas quando estes estão assentados em estabelecimentos instituídos pelos órgãos indigenistas oficiais do Estado, como os aldeamentos e as colônias indígenas do século XIX, os postos e as reservas indígenas do SPI e as atuais terras indígenas pós-Constituição de 1988.

11 No caso das Cartas Guarani esse fato é mais patente ainda na medida em que mesmo em se tratando de documentos de "autoria indígena" a ocupação guarani que o texto apresenta é apenas aquela reconhecida formalmente pelo poder estatal, justamente num momento em que esse reconhecimento se colocava em risco. Entretanto, o mesmo Benedito Calixto, historiador, pintor e, sobretudo "amigo dos índios" para quem as cartas estavam destinadas, em artigo já citado, demonstra ter conhecimento de que também no momento em que os Guarani redigiam essas cartas sua ocupação não respeitava apenas as extensões impostas por esse reconhecimento formal.

12 Todo esse sertão, quase inculto e desabitado, que se entende desde o imenso Vale da Ribeira de Iguape e grande parte do município de Itanhaém, até as margens do Rio Verde e Itararé, abrangendo os municípios de Faxina, Apiaí, Piedade, Una, Itapecerica, etc..., é ainda hoje constantemente percorrido por essa tribo de Guainá [sic: Guarani] nas suas idas e vindas para o litoral. Esta zona pouco povoada do nosso próspero Estado, incontestavelmente uma das mais incultas, foi sempre a preferida pelos índios. Aí se encontram ainda verdadeiros sertões, nos quais o elemento civilizador é por enquanto muito escasso.

13 No litoral, a parte justamente a mais agreste e inculta, entre a Ribeira de Iguape e a bacia fluvial do rio Conceição, foi a zona por eles preferida. Aí estão eles verdadeiramente "em sua casa"; toda essa região é inteiramente despovoada, ninguém os incomoda, a não ser algum caçador que uma ou outra vez penetra nessas florestas. (Calixto, 1905 [1903], pp. 501-502)

14 Assim, se uma das preocupações principais desse dossiê é a de se interrogar sobre as características e particularidades das "fontes indígenas", pode-se dizer que essas duas cartas, apesar de extremamente curtas, desempenham um papel paradigmático para se acercar a uma possível definição. As Cartas Guarani transcritas a seguir não falam apenas da história, como se espera de qualquer fonte, mas atestam, sobretudo, a importância e os desafios da utilização no presente de papeis do passado. 
Foto 1. Índios Guarany do Aldeamento do Rio Itariri, cliché R. Krone, Iguape. Imagem do acervo particular de João Emílio Gerodetti.

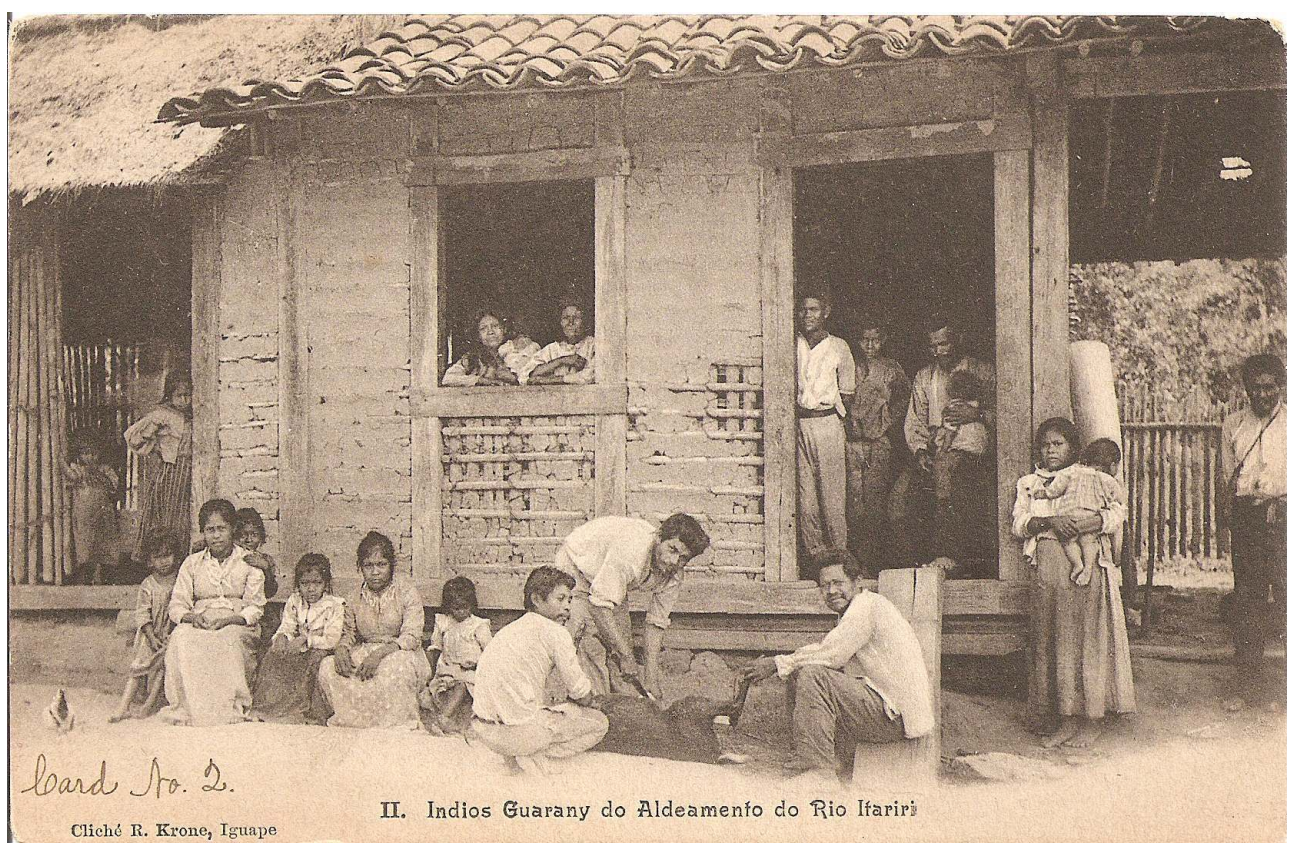

\section{BIBLIOGRAFÍA}

Albuquerque, Cícero Cavalcanti de (1955). Relatório sobre as 'questões de terras entre os fazendeiros agricultores e os remanescentes guaranis das cabeceiras do Igarapé (Córrego ou Riacho) Azeite, no atual município de Itariri'. (MF 341 FT 1514-1519)

Barbosa, Pablo Antunha (2011). Documento técnico final de caracterização histórica das áreas Guarani localizadas na região do Vale do Ribeira, Estado de São Paulo. Brasília: Funai (inédito).

Calixto, Benedito (1905 [1903]). Primitivos aldeamentos e os índios mansos de Itanhaém. Revista do IHGSP, v. X. São Paulo.

Pavez Ojeda, Jorge (2008). Cartas Mapuches. Siglo XIX. Santiago : Ocho Libros-CoLibris.

Pimentel, Spensy K. Pierri, Daniel C. e Bellenzani, Maria Lúcia R. (2010). Relatório circunstanciado de Identificação e Delimitação da Terra Indígena Tenondé Porã. Brasília: Funai (inédito).

\section{ANEXOS}

Illmº Senhor Benedito Calixto

Aldeamento Rio do Peixe de Fevereiro de 1907 
Em primeiro lugar saúdo-vos a V. S ${ }^{\mathrm{a}}$ com a Exmª família a quem Deus guarde também. Venho mui humilde respeitosamente pedir-vos uma proteção além do mais favores que $V$. $\mathrm{S}^{\mathrm{a}}$ tem feito a favor de nós Índios sobre o Aldeamento comunicar-lhe a V. $\mathrm{S}^{\mathrm{a}}$ como Homem grande que é considerado como Político e sabe da lei; avisar-lhe dos absurdos e a imoralidade que tem havido entre o Senhor Bento Manoel Ribeiro residente do Rio do Peixe sendo gente de fora teve a Ousadia de procurar intrigas comigo e quase com todo pessoas Guarany o qual ele declarou que na morada que ele estar ninguém pincha com ele porque ele tem seus documentos passado o qual ele se acha morando dentro do aldeamento faço ver a V. S $\mathrm{S}^{\mathrm{a}}$ ficar ciente que nós índios vive corrido e sem recurso o Snr. Bento Manoel Ribeiro é irmão do Inspetor por nome José Bap ${ }^{\text {ta }}$ Pr. o qual também se acha intimando dentro do Rio do Peixe com papeis falsos e o Inspetor como não gosta de nós Índios só vive a fazer mal e dando parte na Prainha ${ }^{4}$ haveis só por fazer armadilha: por isso eu dou prova entre os Índios todo. Peço-lhe a V. $\mathrm{S}^{\mathrm{a}}$ pelos vossos carinhos filhinhos e pela Dores de Maria que é nossas Mãe fazer ver ao Governo do Estado pedindo-vos proteção e ao mesmo lugar medição para nós ficar ciente e sair da cisma.

E. R. $M^{c e}$

Benedicta Ribeiro

Aldeamento do Rio do Peixe de Fevereiro de 1907

Foto 2. Índios Guarany, cliché R. Krone, Iguape. Imagem do acervo particular de João Emílio Gerodetti.

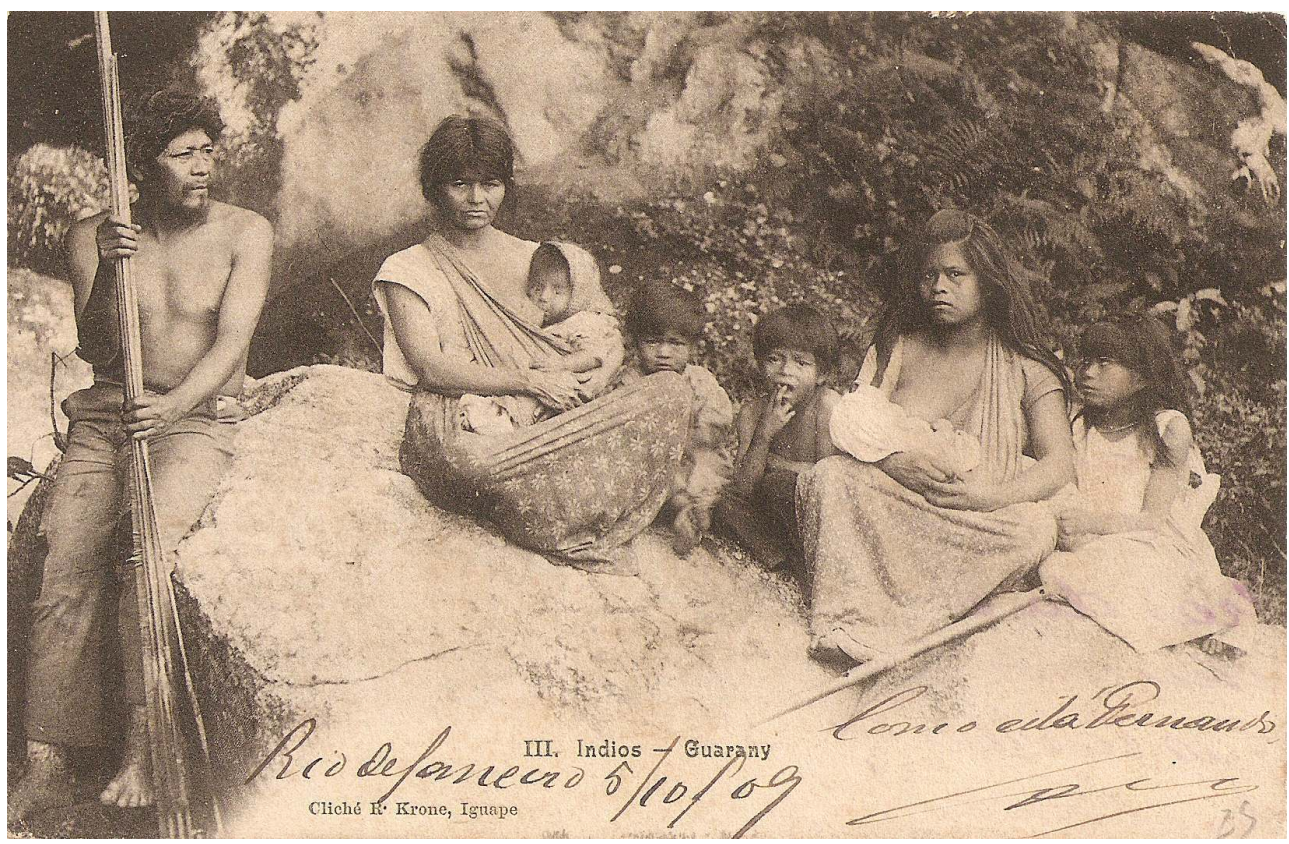


Foto 3. Índios Guarany, cliché R. Krone, Iguape (s/d). Imagem do acervo particular de João Emílio Gerodetti.

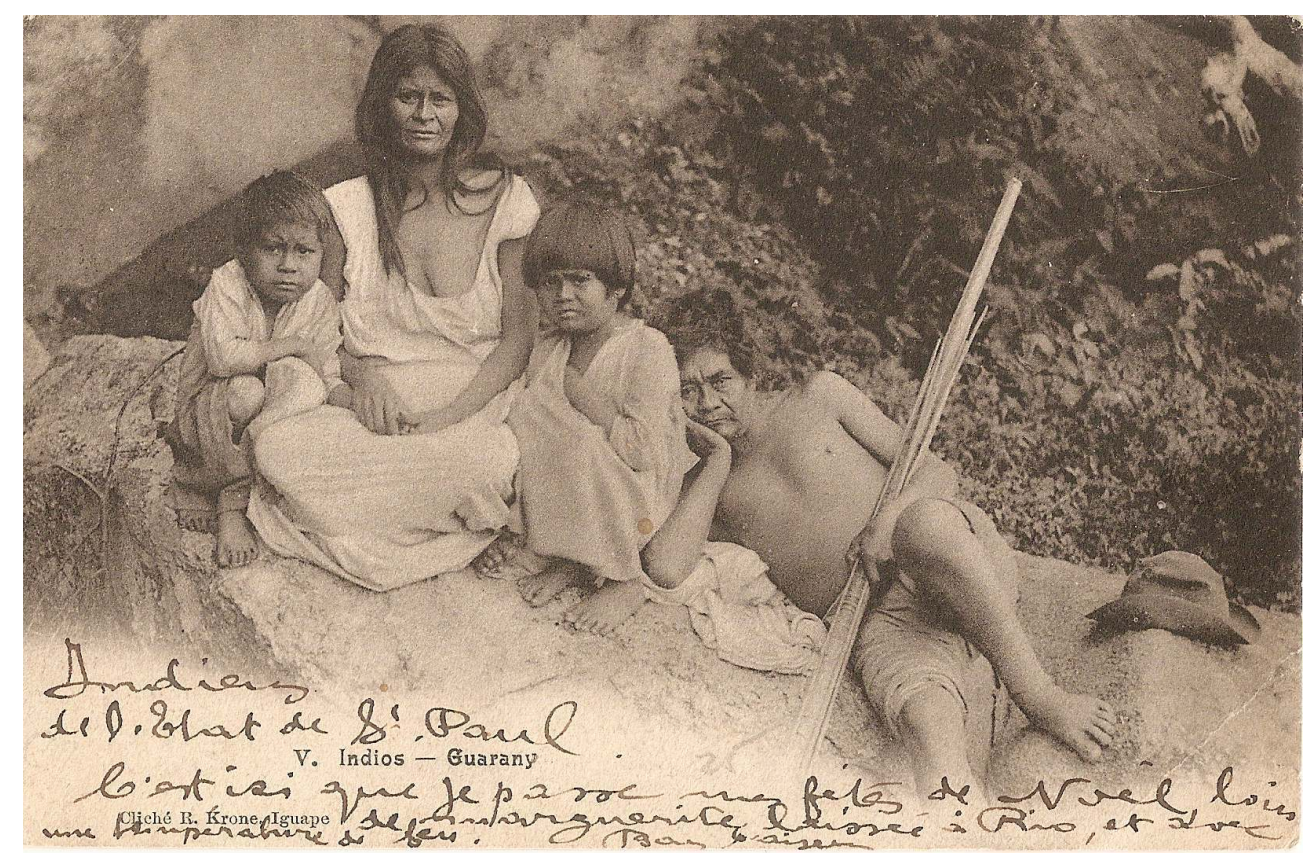

Illmo Senhor Benedito Calixto (s/d).

Atesto José Pupo Ferreira, residente do aldeamento e toda a nação Índios vem debaixo de todo respeito levar ao vosso conhecimento dos absurdos e a imoralidade que tem havido neste aldeamento de algumas pessoas de fora que se acha residente no Aldeamento; 0 qual V. $S^{a}$ sabe muito bem que o Aldeamento é uma Colônia de $1^{a}$ qualidade que foi dada pelo $\mathrm{Ex}^{\mathrm{Q}}$ Monarca D. Pedro que está sempre em vigor para nós Índios o qual hoje nós se acha corrido e insultado e sem ter meios de viver e nem para fazer algumas armadilha para nós sustentar os nossos filhinhos: Nós Indios pede a V.Sa pelo bem da vossa Excelentíssima família e pela chagas de N.S.J.C. além dos mais favores que V.S ${ }^{a}$. tem feito para conosco fazer ver empenhar-se com o Governo do Estado de S. Paulo o que tem se dado neste Aldeamento para ver se assim o Governo se compadeça de nós: Snr. nós Índios vive numa cisma não sabemos direito as divisas do Aldeamento sei que as divisas é do Caracol até o Ribeirão da Fiagem. N.B. o Inspetor que se acha no Rio do Peixe é Homem ruim não gosta de nós as vezes só por se fazer Armadilha ele está oficiando para Prainha. Snr. se o Rio do Peixe é aldeamento então o Inspetor José Baptista Ribeiro está nele o dito disse que ele estar de pé firme porque tem seus documentos o qual eu acho que os documentos que ele tem e mais alguns é falsos nula. Os Índios todo do Aldeamento reclama a pede ao Governo Medição e V. S $S^{a}$ fazer todo possível e reclamação.

E. R. $M^{\text {ce }}$

A rogo de José Pupo Ferreira

Como testemunhas 


\section{NOTAS}

1. Essas duas cartas constam do fundo "Benedito Calixto" do Arquivo Público do Estado de São Paulo (APESP) e foram reproduzidas em Pimentel, Pierri \& Bellenzani 2010; Barbosa 2011.

2. Benedito Calixto nasceu em 14 de outubro de 1853, na Vila de Itanhaém, São Paulo, falecendo em 31 de maio de 1927. Conheceu profundamente, como morador local, todo o sertão de Itanhaém, onde entrou em contato com os Guarani nos aldeamentos do Bananal e do Itariri. Seu vínculo com os Guarani se estreitou a partir de 1900, quando mandou chamá-los no aldeamento do Bananal para servirem de modelo para a seu quadro mais conhecido, "A fundação de Itanhaém". Benedito Calixto também é reconhecido pela importância que seu texto "Os primitivos aldeamentos indígenas e índios mansos de Itanhaen" (1903 [1905]) teve no processo de regularização das terras guarani da capital de São Paulo nos anos 1980. Nesse texto Benedito Calixto descreve com clareza os caminhos e as relações que existiam entre as famílias Guarani que estavam localizadas no litoral e aquelas localizadas no planalto paulista.

3. Liderança Guarani que "lutou" pela demarcação da atual Terra Indígena Serra do Itatins entre 1960 e 1990

4. Atual cidade de Miracatu.

\section{RESÚMENES}

En esta nota introductoria se presentan dos cartas, relacionadas con el problema de la tierra, redactadas por indígenas guaraníes del Estado de São Paulo a inicios del siglo XX. Estas indican los contornos en los cuales se operó el proceso de ocupación y expoliación de los territorios indígenas en el Estado de São Paulo en las primeras décadas del período republicano. Teniendo en cuenta la situación contemporánea de los guaraníes en la costa de Brasil, las dos cartas no solamente desmienten la posición de aquellos que niegan con vehemencia la continuidad histórica de la ocupación guaraní en la región del Vale do Ribeira sino que también revelan una larga trayectoria guaraní en la "lucha" por la conservación de sus territorios tradicionales en el litoral del Estado de São Paulo.

In this introductory note we present two letters, related to the land problem, written by Guarani Indians of the State of São Paulo in the early twentieth century. These letters indicate the contours in which operated the process of occupation and dispossession of indigenous lands in the State of São Paulo in the early decades of the republican period. Considering the contemporary situation of Guarani Indians in the Brazilian coast, the two letters not only refute the position of those who vehemently deny the historical continuity of the Guarani occupation in the Ribeira Valley region but also reveal the Guarani's long history in the "fight" for the preservation of their traditional territories on the coast of the State of São Paulo. 
ÍNDICE

Keywords: Guarani, Indian villages, Indigenous writing, Territorial claims

Palabras claves: Guaraníes, Escritura indígena, Reclamos territoriales

\section{AUTORES}

PABLO ANTUNHA BARBOSA

Museu Nacional-Universidade Federal do Rio de Janeiro, Brasil - Ecole des Hautes Études en Sciences Sociales, Francia. Correo electrónico: pablo.antunha.barbosa@gmail.com

\section{DANIEL CALAZANS PIERRI}

Centro de Estudos Ameríndios (Cesta) da Universidade de São Paulo, Brasil - Centro de Trabalho Indigenista (CTI). Mestrando no Programa de Pós-Graduação em Antropologia Social Universidade de São Paulo, Brasil. Correo electrónico: danibas@gmail.com

\section{MARCO ANTONIO BARBOSA}

Uni-FMU: Faculdade Metropolitanas Unidas, São Paulo, Brasil. Correo electrónico: mabarbosa@fmu.br 